\title{
Effect of apelin on mitosis, apoptosis and DNA repair enzyme OGG $1 / 2$ expression in intestinal cell lines IEC-6 and Caco-2
}

\author{
Hanna Antushevich ${ }^{1}$, Agata Krawczynska ${ }^{1}$, Malgorzata Kapica ${ }^{2}$, \\ Andrzej Przemyslaw Herman ${ }^{1}$, Romuald Zabielski ${ }^{3}$
}

\author{
${ }^{1}$ The Kielanowski Institute of Animal Physiology and Nutrition, Polish Academy of Sciences, \\ Jablonna, Poland \\ ${ }^{2}$ Department of Biochemistry and Animal Physiology, Faculty of Veterinary Medicine, \\ University of Life Sciences in Lublin, Poland \\ ${ }^{3}$ Department of Physiological Sciences, Faculty of Veterinary Medicine, Warsaw University \\ of Life Sciences, Warsaw, Poland
}

\begin{abstract}
Apelin is a regulatory peptide, identified as an endogenous ligand of the Apelin receptor (APJ). Both the apelin and the APJ were detected in brain, lung, heart, mammary gland, kidney, placenta, adipose tissues and the gastrointestinal tract. Apelin is considered an important regulatory gut peptide with a potential physiological role in gastrointestinal cytoprotection, regulation of food intake and drinking behaviour. The aim of the present study was to assess the effect of the apelin on mitosis, apoptosis and the expression of DNA repair enzyme (OGG 1/2), and APJ receptor in intestinal cell lines: rat crypt (IEC-6) and human enterocyte model (Caco-2). The cell cultures were incubated with the apelin- $12\left(10^{-8} \mathrm{M}\right)$ for $4,6,12,24$ and $48 \mathrm{~h}$ and the apoptosis (caspase 3 ), mitosis (Ki-67) and DNA repair enzyme (OGG1/2) markers were studied by Real-Time qRT-PCR and immunofluorescent methods. The results of Real-Time qRT-PCR and immunocytochemical analysis showed that the levels of mRNAs were inversely related to the expression level of corresponding proteins. Immunofluorescent studies revealed inhibitory effect of apelin-12 on apoptosis, mitosis and the expression of OGG1/2 in the intestinal crypt cell line IEC-6. However, in the enterocyte model Caco- 2 cells apelin stimulated apoptosis and mitosis, and reduced OGG1/2 expression. These findings suggest that apelin may be involved in the control of epithelial cell turnover in the gastrointestinal tract. (Folia Histochemica et Cytobiologica 2014, Vol. 52, No. 1, 51-59)
\end{abstract}

Key words: apelin; APJ; caspase 3; Ki-67; OGG 1/2; QPCR; immunofluorescence

\section{Introduction}

In 1998 Tatemoto [1] and co-workers purified from bovine stomach extracts apelin, a ligand of the 'orphan' apelin receptor (APJ). Further studies showed that apelin gene is localized on the human chro-

\footnotetext{
Correspondence address: H. Antushevich M.D.,

The Kielanowski Institute of Animal Physiology and Nutrition of the Polish Academy of Sciences, Laboratory of Molecular Biology, ul. Instytucka 3; 05-110 Jablonna, Poland; tel.: +48 2276533 48; fax: +48 2276533 02; e-mail: antuszewicz@op.pl
}

mosome Xq25-q26.3 and encodes a 77-amino-acid preproprotein [2]. During posttranslational processing of the apelin from the preprohormone several molecular isoforms of the apelin consisting of 36, 17, 13 and 12 amino acids are produced. The smaller fragments of apelin exhibit higher physiological activity than apelin-36 [3,4]. The APJ is a typical 380 amino acid 7-transmembrane domain $\mathrm{G}_{\mathrm{i}}$-coupled receptor displaying a close sequence homology to the angiotensin II receptor type 1 (30-40\% identity in amino acid sequence), although angiotensin II does not interact with the APJ receptor when expressed in Chinese hamster ovary $(\mathrm{CHO})$ cells or in fibroblasts $[1,2]$. 
Apelin and APJ have a widespread distribution in the body. Messenger RNAs encoding apelin and APJ receptor are expressed in heart, lung, placenta, mammary gland, several regions of the central nervous system, adipocytes and the gastrointestinal (GI) tract $[1,2,6,7]$. Apelin is involved in various physiological functions, such as regulation of homeostasis and food intake [8], insulin and CCK secretion [9], cardiovascular system development and cardiac muscle contraction [10], reduction of blood pressure [11] and modulation of the secretion of pituitary hormones [8]. Apelin also stimulates proliferation of gastric epithelial cell line (SIIA) [9] and human vascular smooth muscle cells [12-14], suppresses apoptosis in osteoblastic cell line MC3T3-E1 [15] and protects against cardiomyocyte apoptosis [16]. Apelin has been shown to promote angiogenesis, lymphangiogenesis and tumour growth in vivo [17]. Recently, we have shown that chronic intragastric and intraperitoneal administrations of exogenous apelin can reduce the cell turnover in the rat stomach and small intestine [18]. The aim of the present study was to further elucidate the effects of apelin on the rat small intestinal crypt cell line (IEC-6) and the human enterocyte model cell line (Caco-2) proliferation, apoptosis and the expression of DNA repair enzyme (8-oxoguanine DNA glycosylase, OGG 1/2).

\section{Material and methods}

IEC-6 cell culture. Rat crypt IEC-6 cells (ATCC, Manassas, VA, USA) (14 passage) were grown on coverslips in six-well plastic plates (at a density of $5 \times 10^{5}$ cells $\mathrm{ml}^{-1}$ ) in a standard Dulbecco's modified Eagle's medium (Gibco, Invitrogen Corporation, Carlsbad, CA, USA) consisting of $4.5 \mathrm{~g} / \mathrm{L}$ D-glucose, L-glutamine, $5 \%$ heat inactivated foetal bovine serum (FBS, Gibco), $10 \mathrm{IU} \mathrm{ml}^{-1}$ penicillin $\mathrm{G}$, $100 \mu \mathrm{g} \mathrm{ml}^{-1}$ streptomycin sulphate, $250 \mathrm{ng} \mathrm{ml}^{-1}$ amphotericin B (Sigma-Aldrich, St. Louis, MO, USA) and $10 \mathrm{mg} / \mathrm{L}$ of insulin (Sigma). The cultures were kept at $37^{\circ} \mathrm{C}$ in $5 \% \mathrm{CO}_{2}$ and $90 \%$ relative humidity. The medium was changed once every $24 \mathrm{~h}$ and the cells were cultured until they reached $75 \%$ confluence. The IEC- 6 cells were starved overnight by incubation in standard medium containing $1 \%$ heat inactivated FBS. Synthetic apelin-12 (Phoenix Pharmaceutical Inc., Mannheim, Germany) was added to the cells at the concentration of $10^{-8} \mathrm{M}$, whereas to control cells sterile distilled water was added. After 4, 6, 12, 24 and 48 h, the coverslips with cell layers were removed and analysed by immunofluorescence.

Caco-2 cell culture. Human epithelial colorectal adenocarcinoma Caco-2 cells (ECCC, 50 passage; Sigma) were grown on coverslips in six-well plastic plates (at a density of $5 \times 10^{5}$ cells $\mathrm{ml}^{-1}$ ) in a standard Dulbecco's modified Eagle's medium (Sigma) consisting of $2 \mathrm{mM}$ L-glutamine (Sigma), $1 \%$ non-essential amino acids (Gibco), 10\% heat inactivated FBS (Gibco), $10 \mathrm{IU} \mathrm{ml}^{-1}$ penicillin $\mathrm{G}, 100 \mu \mathrm{g}$ $\mathrm{ml}^{-1}$ streptomycin sulphate and $250 \mathrm{ng} \mathrm{ml}^{-1}$ amphotericin $\mathrm{B}$ (Sigma). The cultures were kept at $37^{\circ} \mathrm{C}$ in $5 \% \mathrm{CO}_{2}$ and $90 \%$ relative humidity. The medium was changed every other day and cultured until cells reached $75 \%$ confluence. The Caco-2 cells were starved over-night in standard medium consisting of $1 \%$ heat inactivated FBS (Gibco). During the experiment, cells from the experimental groups $(n=6)$ were incubated with apelin-12 at the concentration of $10^{-8} \mathrm{M}$; equal volume of sterile water was added to the control group $(\mathrm{n}=6)$. After 4, 6, 12, 24 and $48 \mathrm{~h}$, the coverslips with cells layers were removed and analysed by immunofluorescence.

Assessment of the apelin gene expression. Total RNA from the cell culture was isolated using NucleoSpin ${ }^{\circledR}$ RNA II Kit (MACHEREY-NAGEL Gmbh \& Co; Düren, Germany) according to a manufacturer's instruction. The purity and concentration of isolated RNA were quantified spectrophotometrically by measuring the optical density at 230, 260 and $280 \mathrm{~nm}$ in a NanoDrop 1000 instrument (Thermo Fisher Scientific Inc., Waltham, USA). The RNA integrity was verified by electrophoresis using $1 \%$ agarose gel stained with ethidium bromide. Maxima ${ }^{\mathrm{TM}}$ First Strand cDNA Synthesis Kit for RT-qPCR (Thermo Fisher Scientific Inc.) was used to prepare cDNA synthesis. As a starting material for this PCR synthesis $2 \mu \mathrm{g}$ of total RNA was used.

Real-time RT-PCR was carried out using HOT FIREPol EvaGreen ${ }^{\circledR}$ qPCR Mix Plus (Solis BioDyne, Tartu, Estonia) components and HPLC-grade oligonucleotide primers synthesised by Genomed (Warsaw, Poland). Specific primers for determining the expression of housekeeping genes and the genes of interest were designed using Primer 3 software (Tables 1 and 2). One tube contained: $4 \mu$ l PCR Master Mix $(5 \times), 14 \mu \mathrm{l}$ RNase-free water, $1 \mu \mathrm{l}$ primers $(0.5 \mu \mathrm{l}$ each, working concentration was $0.25 \mu \mathrm{M})$ and $1 \mu \mathrm{l}$ cDNA template. The tubes were run on the Rotor-Gene 6000 (Qiagen, Düsseldorf, Germany). The following protocol was used: $95^{\circ} \mathrm{C}$ in $15 \mathrm{~min}$ for activating Hot Star DNA polymerase and finally the PCR including 30 cycles at $95^{\circ} \mathrm{C}$ in $10 \mathrm{sec}$ for denaturation, $60^{\circ} \mathrm{C}$ in $20 \mathrm{sec}$ for annealing, and $72^{\circ} \mathrm{C}$ in $10 \mathrm{sec}$ for extension. After the cycles, a final melting curve analysis under continuous fluorescence measurements was performed to confirm the specificity of the amplification.

Relative gene expression was calculated using the comparative quantification option of Rotor Gene 6000 software 1.7. (Qiagen). The second differential maximum method [19] was used in this analysis to calculate reaction efficiencies and a set percentage of the maximum fluorescence value to calculate the beginning of the exponential phase. To compensate a variation in cDNA concentrations and the PCR efficiency between tubes, an endogenous control 

and Caco-2

Table 1. Human genes analysed by Real-Time RT-PCR with full names, abbreviations, amplicons' size and primers characteristics

\begin{tabular}{|c|c|c|c|c|}
\hline GenBank Acc. No. & Gene & Amplicon size [bp] & Forward/reverse & Sequence $5^{\prime} \rightarrow 3$ ' \\
\hline \multirow[t]{2}{*}{ NM_001256799.1 } & \multirow{2}{*}{$\begin{array}{c}\text { GAPDH } \\
\text { glyceraldehyde }-3-\text { phosphate } \\
\text { dehydrogenase }\end{array}$} & \multirow[t]{2}{*}{131} & Forward & GCCAAAAGGGTCATCATCTC \\
\hline & & & Reverse & GGTGCTAAGCAGTTGGTGGT \\
\hline \multirow[t]{2}{*}{ NM_001101.3 } & \multirow{2}{*}{$\begin{array}{c}\text { ACTB } \\
\text { beta actin }\end{array}$} & \multirow[t]{2}{*}{116} & Forward & СТCTTCCAGCCTTCCTTCCT \\
\hline & & & Reverse & AGCACTGTGTTGGCGTACAG \\
\hline \multirow[t]{2}{*}{ NM_000943 } & \multirow{2}{*}{$\begin{array}{c}\text { PPIC } \\
\text { cyclophilin C }\end{array}$} & \multirow[t]{2}{*}{146} & Forward & ACTATGGCATTGGGTGGGTC \\
\hline & & & Reverse & GTGCACCACTGTCATCCCAT \\
\hline \multirow[t]{2}{*}{ NM_004346 } & \multirow{2}{*}{$\begin{array}{c}\text { CASP3 } \\
\text { caspase 3, apoptosis-related } \\
\text { cysteine peptidase }\end{array}$} & \multirow[t]{2}{*}{112} & Forward & TGCTATTGTGAGGCGGTTGT \\
\hline & & & Reverse & TCACGGCCTGGGATTTCAAG \\
\hline \multirow[t]{2}{*}{ NM_002417 } & \multirow{2}{*}{$\begin{array}{c}\text { Ki-67 } \\
\text { antigen identified by } \\
\text { monoclonal antibody Ki-67 }\end{array}$} & \multirow[t]{2}{*}{154} & Forward & AGCACGTCGTGTCTCAAGAT \\
\hline & & & Reverse & TGAGTCATCTGCGGTACTGTC \\
\hline \multirow[t]{2}{*}{ NM_002542 } & \multirow{2}{*}{$\begin{array}{c}\text { OGG1 } \\
\text { sapiens 8-oxoguanine } \\
\text { DNA glycosylase }\end{array}$} & \multirow[t]{2}{*}{145} & Forward & ACATTGCCCAACGTGACTACA \\
\hline & & & Reverse & GCACTGAACAGCACCGCTT \\
\hline
\end{tabular}

Table 2. Rat genes analysed by Real-Time RT-PCR with full names, abbreviations, amplicons' size and primers characteristics

\begin{tabular}{|c|c|c|c|c|}
\hline GenBank Acc. No. & Gene & Amplicon size [bp] & Forward/ reverse & Sequence $5^{\prime} \rightarrow 3$ ' \\
\hline \multirow[t]{2}{*}{ NM_017008.3 } & \multirow{2}{*}{$\begin{array}{c}\text { GAPDH } \\
\text { glyceraldehyde-3-phosphate } \\
\text { dehydrogenase }\end{array}$} & \multirow[t]{2}{*}{161} & Forward & GAGGACCAGGTTGTCTCCTG \\
\hline & & & Reverse & ATGTAGGCCATGAGGTCCAC \\
\hline \multirow[t]{2}{*}{ NM_031144.3 } & \multirow{2}{*}{$\begin{array}{c}\text { ACTB } \\
\text { beta actin }\end{array}$} & \multirow[t]{2}{*}{148} & Forward & CCTGGGTATGGAATCCTGTG \\
\hline & & & Reverse & СTTCTGCATCCTGTCAGCAA \\
\hline \multirow[t]{2}{*}{ NM_001004215.1 } & \multirow{2}{*}{$\begin{array}{c}\text { PPIC } \\
\text { cyclophilin C }\end{array}$} & \multirow[t]{2}{*}{150} & Forward & CTGGCAACAGGAGAGAAAGG \\
\hline & & & Reverse & CTTGGTGACGGACAAGGTCT \\
\hline \multirow[t]{2}{*}{ NM_012922 } & \multirow{2}{*}{$\begin{array}{c}\text { CASP3 } \\
\text { caspase 3, apoptosis- } \\
\text {-related cysteine peptidase }\end{array}$} & \multirow[t]{2}{*}{90} & Forward & TCTACCGCACCCGGTTACTA \\
\hline & & & Reverse & CGCGTACAGTTTCAGCATGG \\
\hline \multirow[t]{2}{*}{ NM_001271366 } & \multirow{2}{*}{$\begin{array}{c}\text { Ki-67 } \\
\text { antigen identified by } \\
\text { monoclonal antibody Ki-67 }\end{array}$} & \multirow[t]{2}{*}{113} & Forward & ACCGCCTCAGAGATTTTGGG \\
\hline & & & Reverse & TGTTTGATGCTCTGCCGTCT \\
\hline \multirow[t]{2}{*}{ NM_030870 } & \multirow{2}{*}{$\begin{array}{c}\text { OGG1 } \\
\text { sapiens } \\
\text { 8-oxoguanine DNA } \\
\text { glycosylase }\end{array}$} & \multirow[t]{2}{*}{111} & Forward & AGACATCGCAGACTAAGGGC \\
\hline & & & Reverse & CACTGAACAGCACTGCTTGG \\
\hline
\end{tabular}

gene was assayed in each sample and used for normalization. Initially, three housekeeping genes: GAPDH, $\beta$-actin, and PPIC were tested. The BestKeeper algorithm was used to determine the most stable housekeeping gene, for normalizing genes of interest expression. The BestKeeper program is based on the pair-wise correlation analysis of all pairs of candidate genes [20] and calculates variations of all reference genes [SD $( \pm \mathrm{Ct})]$. GAPDH was chosen as the best endogenous control gene, showing the lowest $\mathrm{SD}( \pm \mathrm{Ct})$ value and a good correlation coefficient with the remaining analysed housekeeping genes.

The results are presented as relative gene expression of the target gene vs. housekeeping gene (delta CT) and me- dian \pm SD. The average relative gene expression in control groups was set to 1.0.

Immunofluorescence analysis. For the determination of APJ, and expression of Ki-67 (mitosis marker), caspase 3 (CAS3, apoptosis marker) and OGG 1/2 (DNA repair enzyme) the IEC- 6 and Caco- 2 cells were fixed in cold $\left(4^{\circ} \mathrm{C}\right)$ $4 \%$ formalin for $15 \mathrm{~min}$, permeabilised at room temperature (RT) in $1 \%$ Triton X-100/PBS for $10 \mathrm{~min}$. and blocked at RT for $10 \mathrm{~min}$. with $0.25 \% \mathrm{BSA} / \mathrm{PBS}$ (Sigma). For determination of APJ receptor expression, the coverslips with cells layer were incubated with primary polyclonal rabbit antihuman 
and antirabbit APJ antibodies (dilution 1:100, Abcam, UK) for $1 \mathrm{~h}$ at RT. Following the incubation, the coverslips were washed three times in PBS and incubated in darkness for $1 \mathrm{~h}$ at RT. with secondary antibody DyLight 488 conjugated AffiniPure Donkey Anti-Rabbit IgG (dilution 1:500, Jackson Immuno Research, West Grove, PA, USA). For the determination of active mitosis and apoptosis, the cells were incubated in darkness with Ki-67 or Cas-3 antibody (1:400) conjugated with dye fluorescein isothiocyanate FITC (BD Bioscience, USA) for $1 \mathrm{~h}$ at RT.

For the determination of OGG $1 / 2$ expression, the cells were incubated with primary polyclonal goat antihuman and antyrabbit OGG 1/2 antibodies (dilution 1:300, Santa Cruz Biotechnology, Dallas, TX, USA) for $1 \mathrm{hr}$. at RT. Following the incubation, the coverslips were washed three times in PBS and then incubated with secondary antibody FITC conjugated Rb Anti-Goat IgG (dilution 1:50, Calbiochem, EMD Millipore, Billerica, MA, USA) in darkness for $1 \mathrm{hr}$. at RT.

To calculate total cell number, coverslips with cells layer was incubated for $10 \mathrm{~min}$. in darkness with 7-aminoactinomycin D (7AAD) (1:1000, Sigma).

After rinsing three times in PBS the labelled cells were coated with immunofluore mounting-medium (Sigma) and covered with coverslips. Prior to the visualization the cells were stored at $4^{\circ} \mathrm{C}$ in darkness.

For semi-quantitative analysis, 10 images (for apoptosis, mitosis and OGG $1 / 2$ in cell lines) were collected by confocal microscope $(40 \times$ objective, LSM Pascal, ZEISS). The fluorescence intensity was measured and-calculated using AxioVision Release 4.1 software (Zeiss). Mitotic, apoptotic, DNA damaged and 7AAD-stained cells were counted manually, and the ratio of examined cells number to total cell numbers was calculated.

Statistical analysis. All data were expressed as means \pm SD Differences between groups were determined by one-way analysis of variance ANOVA followed by the Tukey-Kramer post hoc test for protein expression and by the Student's T-test for gene expression (Statistica v. 9.0, StatSoft, Cracow, Poland). In all statistical analyses, $P<0.05$ was taken as the level of significance.

\section{Results}

\section{Expression of APJ receptor in IEC-6 and Caco-2 cells}

The immunofluorescent staining documented the presence of APJ receptor protein in IEC- 6 and Caco- 2 cell lines. The APJ was located on the cell membrane surface (Figure 1A, E).

\section{Effects of apelin-12 on the apoptosis, mitosis and DNA repair enzyme OGG 1/2 in IEC-6 cells}

The treatment of IEC- 6 cells with apelin-12 significantly decreased the number of apoptotic cells after incubation for 4, 24 and $48 \mathrm{~h}$ (Table 3). However, after incubation for $6 \mathrm{~h}$ an increased number of apoptotic cells in culture was observed (Table 3, Figure 1B).

Addition of apelin-12 to the IEC-6 cell culture medium decreased mitotic index after treatment for 12 and $48 \mathrm{~h}$ No effect of apelin-12 on IEC- 6 cells mitotic rate was observed after incubation for 4, 6 and $24 \mathrm{~h}$ (Table 3, Figure 1C).

Treatment of IEC- 6 cells with apelin- 12 reduced the expression of OGG1/2 protein after 4 and $12 \mathrm{~h}$ However, incubation of cells with apelin- 12 for $24 \mathrm{~h}$ increased the expression of OGG1/2 (Table 3, Figure 1D).

\section{Effects of apelin-12 on the CAS3, Ki-67 and OGG 1 gene expression in IEC-6 cells}

Real-Time PCR analysis showed noeffect of apelin-12on CAS3 gene expression in IEC-6 cells line (Figure 2A). Incubation of IEC-6 cells with apelin-12 (Figure 2B) decreased Ki-67 gene expression level after treatment for $12 \mathrm{~h}$ compared to the control group. No effect of apelin- 12 on Ki- 67 gene expression in IEC- 6 cells after $4,6,24$ and 48 h of incubation was observed. Stimulation of IEC- 6 cells by apelin-12 reduced OGG1 gene expression level after incubation for $6 \mathrm{~h}$ compared to control (Figure 2C). No effect of apelin-12 on the OGG1 gene expression in IEC-6 cells line after 4, 12, 24 and $48 \mathrm{~h}$ was found.

\section{Effects of apelin-12 on the apoptosis, mitosis and DNA repair enzyme OGG 1/2 in Caco-2 cells}

Incubation of Caco- 2 cells in the presence of apelin-12 significantly decreased the number of apoptotic cells in culture after treatment for $4 \mathrm{~h}$ (Table 4). Longer incubations, for 6, 12 and $48 \mathrm{~h}$ showed an opposite effect. No difference in the number of apoptotic cell was observed after incubation for $24 \mathrm{~h}$ (Table 4, Figure 1F).

Incubation of Caco-2 cells with apelin-12 led to significant increase in the number of mitotic cells after treatment for 4, 12 and $24 \mathrm{~h}$ No effect of apelin-12 on Caco-2 cells mitosis was observed after incubation for 6 and 48 h (Table 4, Figure 1G).

Treatment of Caco- 2 cells with apelin-12 reduced the expression of OGG $1 / 2$ after 6 and $24 \mathrm{~h}$ No effect on OGG1/2 expression was observed after incubation with apelin-12 for 4, 12 and $48 \mathrm{~h}$ (Table 4, Figure $1 \mathrm{H}$ ).

\section{Effects of apelin-12 on the CAS3, KI-67 and OGG 1 gene expression in the Caco-2 cells}

Incubation of Caco-2 cells with apelin-12 (Figure 2D) increased the level of CAS3 gene expression after treatment for $48 \mathrm{~h}$, however, no effect of apelin-12 was observed after incubation for 4, 6, 12 and $24 \mathrm{~h}$. 

and Caco-2

Table 3. Caspase-3, Ki-67 and OGG $1 / 2$ expression in IEC-6 cells incubated with apelin-12 (10-8 M)

\begin{tabular}{|l|l|c|c|c|c|c|}
\hline \multicolumn{9}{|c|}{ Time of incubation } \\
\hline & Groups & $\mathbf{4 h}$ & $\mathbf{6 ~ h}$ & $\mathbf{1 2} \mathbf{~ h}$ & $\mathbf{2 4} \mathbf{~ h}$ & $\mathbf{4 8 ~ h}$ \\
\hline Apoptosis & Control & $15.9 \pm 1.1$ & $13.4 \pm 0.7$ & $14.9 \pm 1.5$ & $17.2 \pm 0.9$ & $18.5 \pm 1.1$ \\
\hline & Apelin & $11.6 \pm 1.5^{* * *}$ & $16.8 \pm 1.9^{* * *}$ & $14.1 \pm 1.7$ & $13.8 \pm 1.1^{* * *}$ & $15.5 \pm 1.5^{* * *}$ \\
\hline Mitosis & Control & $22.1 \pm 1.5$ & $25.9 \pm 6.6$ & $31.6 \pm 4.8$ & $25.4 \pm 2.8$ & $28.7 \pm 1.8$ \\
\hline & Apelin & $21.4 \pm 2.9$ & $22.2 \pm 1.6$ & $18.7 \pm 2.6^{* * *}$ & $26.4 \pm 2.7$ & $20.4 \pm 2.4^{* * *}$ \\
\hline OGG 1/2 & Control & $16.9 \pm 2.2$ & $10.2 \pm 1.4$ & $8.7 \pm 0.7$ & $4.1 \pm 0.8$ & $4.5 \pm 0.5$ \\
\hline & Apelin & $4.6 \pm 0.8^{* * *}$ & $8.8 \pm 1.7$ & $3.7 \pm 0.7^{* * *}$ & $5.7 \pm 0.7^{* * *}$ & $3.1 \pm 0.6$ \\
\hline
\end{tabular}

Values express the percentage of a number of caspase-3, Ki-67 or OGG 1/2 immunoreactive cells compared to the total number of cells counted on the basis of 7-AAD-related fluorescence. Data are presented as means $\pm \operatorname{SD}(n=6) .{ }^{* * *}$ statistically significant difference between the apelin and control group as estimated by one-way ANOVA followed by Tukey's test, $\mathrm{P}<0.001$.
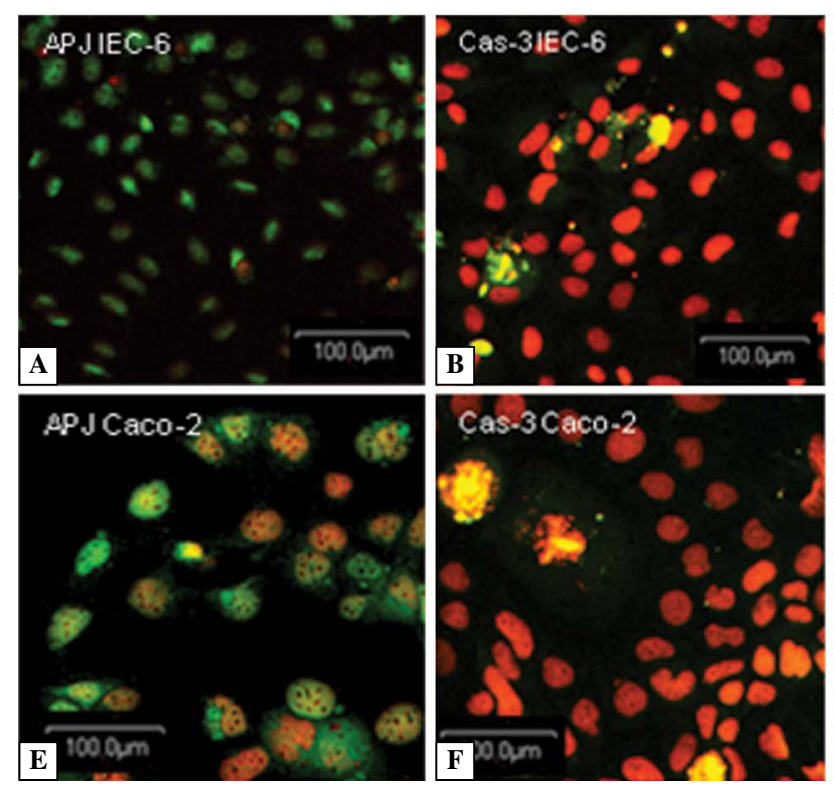
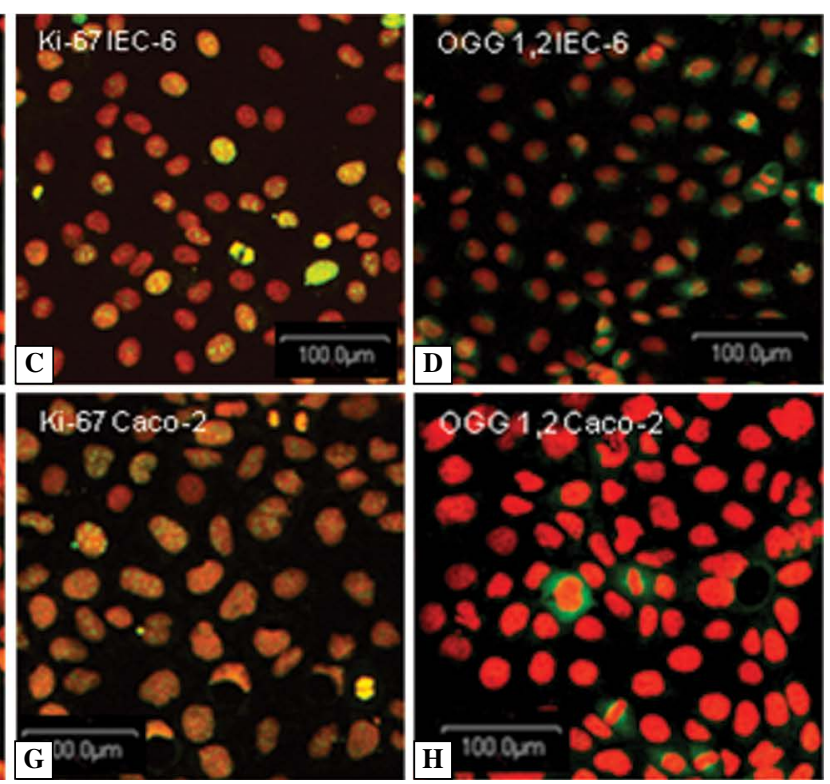

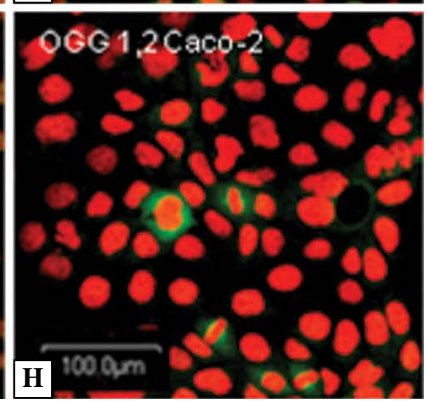

Figure 1. Expression of APJ (A and E), Cas-3 (B and F), Ki-67 (C and G) and OGG1/2 (D and H) proteins in IEC-6 (A-D) and Caco-2 (E-H) cell lines by immunofluorescent technique. APJ receptor expression was visualized by antyrabbit APJ antibodies with secondary antibody DyLight 488 conjugated AffiniPure Donkey Anti-Rabbit IgG (green fluorescence), caspase-3 expression visualized by Cas-3 antibody conjugated with FITC (green fluorescence), mitosis was visualized by Ki-67 antibody conjugated with FITC (green fluorescence), and expression of DNA repair enzyme OGG 1,2 was visualized by anti-rabbit OGG 1,2 antibody with secondary antibody Rb Anti-Goat IgG (green fluorescence) in IEC-6 and Caco- 2 cells. Red fluorescence shows cell nuclei stained with 7-aminoactinomycin D (7AAD) (1:1000). Bar $=100 \mu \mathrm{m}$

Increased KI-67 gene expression was observed after incubation of Caco-2 cells with apelin-12 for $48 \mathrm{~h}$ (Figure 2E), however, no effect of apelin-12 was observed after incubation for 4, 6, 12, and $24 \mathrm{~h}$ Treatment Caco-2 cells with apelin-12 increased OGG1 gene expression after incubation for $6 \mathrm{~h}$, $12 \mathrm{~h}$, and $48 \mathrm{~h}$ (Figure 2F). No effect of apelin-12 on gene expression of OGG1 was observed in Caco-2 cells after incubation for 4 and $24 \mathrm{~h}$.

\section{Discussion}

We studied effects of apelin-12 on the processes important in cell renewal (apoptosis, mitosis and DNA repair) in rat intestinal crypt IEC-6 and a human enterocyte model Caco- 2 cell lines. Our immunofluorescence data showed that APJ receptor was expressed on enterocyte membrane surface in both IEC-6 and Caco-2 cell lines. We previously reported that in rat 

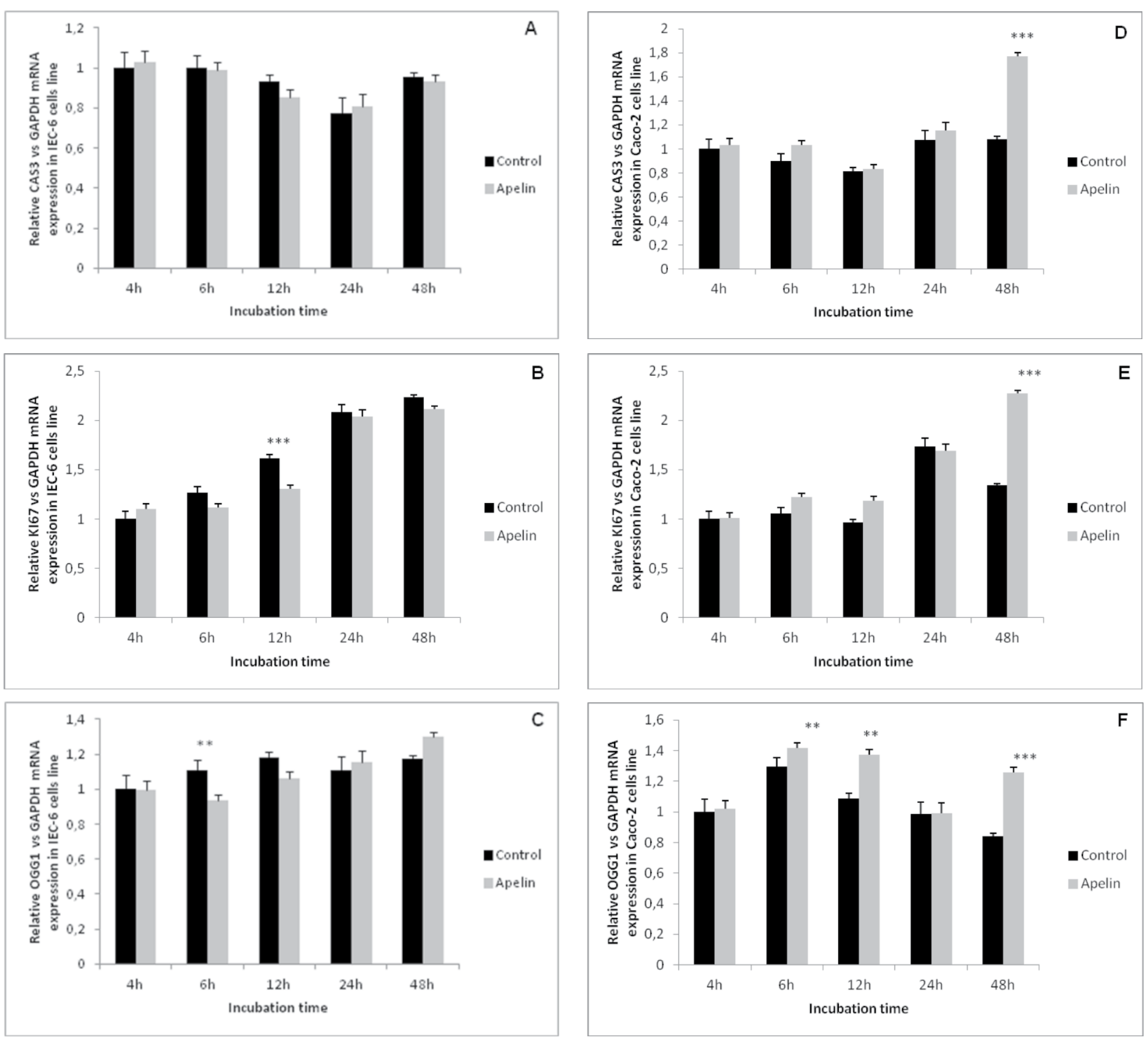

Figure 2. Relative gene expression of CAS3 (A, D), KI-67 (B, E) and OGG1/2 (C, F) genes in IEC-6 (A,B,C) and Caco-2 (D-F) cell lines incubated with apelin-12 $\left(10^{-8} \mathrm{M}\right)$ for the indicated times. Values are given as means $\pm \mathrm{SD}(\mathrm{n}=6)$. The relative apoptosis, mitosis and OGG $1 / 2$-expression in cells was quantified $v$ s. control group by the Student's T-test; ${ }^{* *} \mathrm{P}<0.01$; ${ }^{* * *} \mathrm{P}<0.001$

Table 4. Caspase-3, Ki-67 and OGG 1/2 expression in Caco-2 cells incubated with apelin-12 (10-8 M)

\begin{tabular}{|l|l|c|c|c|c|c|}
\hline \multicolumn{9}{|c|}{ Time of incubation } \\
\hline & Groups & $\mathbf{4} \mathbf{~ h}$ & $\mathbf{6 ~ h}$ & $\mathbf{1 2} \mathbf{~ h}$ & $\mathbf{2 4} \mathbf{~ h}$ & $\mathbf{4 8 ~ h}$ \\
\hline Apoptosis & Control & $7.67 \pm 0.62$ & $5.21 \pm 0.24$ & $5.44 \pm 0.98$ & $5.64 \pm 0.90$ & $3.59 \pm 0.31$ \\
\hline & Apelin & $5.10 \pm 0.41^{* * *}$ & $6.06 \pm 0.48^{* * *}$ & $7.45 \pm 0.46^{* * *}$ & $6.22 \pm 0.72$ & $5.89 \pm 0.89^{* * *}$ \\
\hline Mitosis & Control & $3.30 \pm 0.28$ & $5.46 \pm 0.48$ & $3.80 \pm 0.46$ & $3.37 \pm 0.85$ & $3.90 \pm 0.69$ \\
\hline & Apelin & $6.45 \pm 0.64^{* * *}$ & $4.67 \pm 0.81$ & $5.71 \pm 0.86^{* * *}$ & $6.58 \pm 1.25^{* * *}$ & $3.47 \pm 0.73$ \\
\hline OGG 1/2 & Control & $3.85 \pm 0.65$ & $12.80 \pm 1.48^{* * *}$ & $12.32 \pm 0.85$ & $3.52 \pm 0.26^{* * *}$ & $1.90 \pm 0.54$ \\
\hline & Apelin & $4.29 \pm 0.61$ & $10.13 \pm 0.63$ & $11.57 \pm 0.75$ & $2.21 \pm 0.40$ & $2.14 \pm 0.38$ \\
\hline
\end{tabular}

Description of symbols as for Table 3. 
APJ was abundantly expressed in the smooth muscle layer of the stomach, duodenum and colon [7]. APJ immunostaining was associated primarily with the cell membrane, cytoplasm, venules of intestinal villi, and in endothelial cells [7]. The presence of APJ receptor on the surface of these model intestinal cells suggests that apelin may be involved in the regulation of a number of basic functions of cell, including mitosis, apoptosis and DNA repair enzyme expression.

The apelin was found to stimulate [12-15] or inhibit [21] cell proliferation, depending on a cell line. Wang and co-workers [9] showed that apelin stimulated cell proliferation in human gastric epithelial cell line SIIA, while Han et al., [22] reported that acute exposure of rat pups to hypoxia decreased gastric and colonic epithelial cell proliferation, while hypoxia in combination with apelin administration resulted in increased proliferation of epithelial cells and improved cell survival [22].

In the present study we found that apelin-12 inhibited cell mitosis in intestinal crypt model - IEC-6 cell line, and stimulated cell proliferation in the enterocyte model - Caco- 2 cell line, both at the transcriptional and posttranscriptional level. Results of Real-Time RT-PCR and immunocytochemical analysis showed that the reduction of protein expression in culture was accompanied by increased gene expression after longer incubation time. This suggest that the decreasing level of protein in the cell could send signal to the nuclei to increase transcription process. The different effects of apelin on the individual cell lines indicate that in undifferentiated (IEC-6) and mature (Caco-2) enterocytes apelin could initiate different signalling pathways associated with cell division. We did not investigate mechanisms of apelin action on proliferative signalling pathway, but literature data show that apelin-13 can stimulate vascular smooth muscle cell proliferation by promoting the G1-S phase transition, and that this effect is mediated in part by an apelin-pERK1/2-cyclin D1 signal cascade [12], that stimulates the same type of cells through PI3K/Akt signalling transduction pathway [13]. Apelin stimulated proliferation of mouse osteoblastic MC3T3-E1 cells and these actions was mediated via JNK and PI3-K/ /Akt signalling pathways [15]. Furthermore, it was reported [14] that treatment of human umbilical vein endothelial cells with apelin increased endothelial cell migration and proliferation in a dose-dependent manner. Apelin suppressed the proliferation of endothelial cells independently of the vascular endothelial growth factor VEGF/VEGF receptor and appeared to be a prerequisite factor for hypoxia-induced retinal angiogenesis [21]. Based on these results, it seems that apelin can affect the cell cycle interacting with pho- sphatidylinositol 3 kinase (PI3-K) pathway activity, but more detailed data are needed to determine the signalling pathway involved in apelin action in IEC-6 and Caco-2 cell lines used in our study.

To examine cell apoptosis we investigated activated caspase-3 expression. Caspase-3 is a critical executioner of apoptosis, as it is either partially or totally responsible for proteolysis of many key proteins such as the nuclear enzyme poly (ADP-ribose) polymerase (PARP) [23]. Our results showed that apelin-12 reduces apoptosis in IEC-6 and delayed the onset of apoptosis in Caco-2 for a few hours, but thereafter the intensity of apoptosis increased. The changes observed at the level of protein expression in IEC-6 cells did not parallel gene transcription. During the entire course of the study, the CAS3 gene expression in IEC-6 cells was silenced. However, the difference observed at the level of protein may be due to the activation by other genes or proteins than directly influence CAS3 gene expression or due to the lack of required proteins. In Caco- 2 cells, stimulation of CAS3 gene expression was observed only after incubation for $48 \mathrm{~h}$, while at earlier times the changes were noticed only at the level of protein. Similarly to IEC-6 cells, those effects could be associated with the lack of protein needed and the action of other signalling pathways initiated by apelin.

Inhibitory action of apelin on cell apoptosis in various tissues has been previously reported. Apelin-13 reduced apoptosis in bone marrow mesenchyme stem cells (BMSCs) by a concentration-dependent manner and anti-apoptotic effects were blocked by inhibiting the MAPK/ERK1/2 and PI3K/Akt signalling pathways [24]. It was also reported that apelin suppresses apoptosis of human and mouse osteoblasts, and the anti-apoptotic action is mediated via the APJ/PI-3 kinase/Akt signalling pathway $[15,25]$. Apelin also inhibited human vascular smooth muscle cells (VSMCs) apoptosis induced by serum deprivation and increased Bcl-2 protein expression, but decreased Bax protein expression [26]. Apelin also activated in VSMCs the extracellular signal-regulated protein kinase (ERK) and Akt (a downstream effector of phosphatidylinositol 3-kinase) [26]. These findings were confirmed in rat cardiomyocytes by Zhang et al. [16]. Pretreatment with apelin-13 inhibited cardiomyocyte apoptosis induced by glucose deprivation and increased Akt and mTOR phosphorylation. At the same time apelin-13 up-regulated Bcl-2 protein expression and down-regulated Bax and cleaved caspase-3 expression [16]. On the basis of these reports we can assume that apelin can stimulate the synthesis of anti-apoptotic proteins from Bcl-2 family and can interact with phosphatidylinositol 3-kinase protein. 
We demonstrated that apelin also affected the expression of the OGG $1 / 2$, DNA oxidative damage repair enzyme. The oxidation of DNA was shown to dramatically increase the 8-oxo-7,8-dihydroguanine (8-oxoG) production which was implicated in tumorigenesis, aging and various degenerative disorders [27-29]. The cells are equipped with many DNA repair mechanisms to counteract the deleterious effects of reactive oxygen species (ROS). The 8-oxoG is repaired mainly by Base Excision Repair pathway initiated by a lesion-specific DNA glycosylase [30]. In eukaryotic cells, the major 8-oxoG glycosylase is OGG1/2 protein. The OGG1A splice variant is the most prevalent form and localizes to the nucleus, whereas the OGG2A splice variant is targeted to the mitochondria [31]. There are no reports concerning the effects of the apelin or other regulatory peptides on the DNA repair process, but our results showed that apelin-12 generally inhibited DNA repair enzyme OGG $1 / 2$ expression in IEC-6 and Caco- 2 cell lines. In IEC-6 line there was a noticeable reduction in OGG enzyme both at the protein and as well as gene expression level. On the other hand, in Caco-2 cells OGG protein expression did not parallel the changes in transcription of gene encoding this protein. The effect of apelin on OGG synthesis may be induced by it influence on the nucleoside polymerization in the studied cell lines. Low expression of the DNA repair enzyme in intestinal cell lines suggests that apelin may affect DNA repair process and can have cytoprotective properties, although this notion requires further detailed study.

In summary, our in vitro study showed that apelin suppressed apoptosis, mitosis and OGG1/2 expression in rat intestinal crypt cell line and stimulated apoptosis and mitosis and suppressed OGG1/2 expression in human enterocyte model cell line. This suggests that apelin may be involved in the regulation of cell turnover in the gastrointestinal tract epithelium, however, further studies are needed to clarify the molecular mechanism of apelin action in the intestinal epithelium.

\section{Acknowledgments}

This work was supported by Grant N N311 082737 from the Polish Ministry for Research and Higher Education.

\section{References}

1. Tatemoto K, Hosoya M, Habata $\mathrm{Y}$ et al. Isolation and characterization of a novel endogenous peptide ligand for the human APJ receptor. Biochem Biophys Res Commun. 1998;251:471-476.

2. Medhurst AD, Jennings CA, Robbins MJ et al. Pharmacological and immunohistochemical characterization of the APJ receptor and its endogenous ligand apelin. $J$ Neurochem. 2003;84:1162-1172.
3. De Mota N, Lenkei Z, and Llorens-Cortes C. Cloning, pharmacological characterization and brain distribution of the rat apelin receptor. Neuroendocrinology. 2000;72:400-407.

4. Lee D. K, Cheng R, Nguyen T et al. Characterization of apelin, the ligand for the APJ receptor.J Neurochem. 2000;74:34-41.

5. O'Dowd BF, Heiber M, Chan A et al. A human gene that shows identity with the gene encoding the angiotensin receptor is located on chromosome 11. Gene. 1993;136:355.

6. Foldes G, Horkay F, Szokodi I et al. Molecular and functional characteristics of APJ. Tissue distribution of mRNA and interaction with the endogenous ligand apelin. J Biol Chem. 2000;275:21061-21067.

7. Kapica M, Jankowska A, Antushevich $\mathrm{H}$ et al. The effect of exogenous apelin on the secretion of pancreatic juice in anaesthetized rats. J Physiol Pharmacol. 2012;63:53-60.

8. Taheri S, Murphy K, Cohen M et al. The effects of centrally administered apelin-13 on food intake, water intake and pituitary hormone release in rats. Biochem Biophys Res Commun. 2002;291:1208-1212.

9. Wang G, Anini Y, Wei W et al. Apelin, a new enteric peptide:localization in the gastrointestinal tract, ontogeny, and stimulation of gastric cell proliferation and of cholecystokinin secretion. Endocrinology. 2004;145:1342-1348.

10. Ishida J, Hashimoto T, Hashimoto $\mathrm{Y}$ et al. Regulatory roles for APJ, a seven-transmembrane receptor related to angiotensin-type 1 receptor in blood pressure in vivo.J Biol Chem. 2004;279:26274-26279.

11. Tatemoto K, Takayama K, Zou MX et al. The novel peptide apelin lowers blood pressure via a nitric oxide-dependent mechanism. Regul Pept. 2001;99:87-92.

12. Li F, Li L, Qin X et al. Apelin-induced vascular smooth muscle cell proliferation:the regulation of cyclin D1. Front Biosci. 2008;13:3786-3792.

13. Liu C, Su T, Li F et al. PI3K/Akt signaling transduction pathway is involved in rat vascular smooth muscle cell proliferation induced by apelin-13. Acta Biochim Biophys Sin (Shanghai). 2010;42:396-402.

14. Kunduzova O, Alet N, Delesque-Touchard N et al. Apelin/ APJ signaling system:a potential link between adipose tissue and endothelial angiogenic processes. FASEB J. 2008;22:4146-4153.

15. Tang SY, Xie H, Yuan LQ et al. Apelin stimulates proliferation and suppresses apoptosis of mouse osteoblastic cell line MC3T3-E1 via JNK and PI3-K/Akt signaling pathways. Peptides. 2007;28:708-718.

16. Zhang Z, Yu B, Tao GZ. Apelin protects against cardiomyocyte apoptosis induced by glucose deprivation. Chin Med J. (Engl). 2009;122:2360-2365.

17. Srujana R, Della-Fera M, Kasser T, Warren W, Baile CA. Emerging role of apelin as a therapeutic target in cancer:a patent review. Recent Pat Anticancer Drug Discov. 2011;6:367-372.

18. Antushevich H, Pawlina B, Kapica M et al. Influence of fundectomy and intraperitoneal or intragastric administration of apelin on apoptosis, mitosis, and DNA repair enzyme OGG $1 / 2$ expression in adult rats GI tract and pancreas. $J$ Physiol Pharmacol. 2013;64:423-428.

19. Rasmussen R. Quantification on the LightCycler. In:Meuer $\mathrm{S}$, Wittwer C, Nakagawara K, ed. Rapid Cycle Real-Time PCR Methods and Applications. Berlin 2001:21-34.

20. Pfaffl MW, Tichopad A, Prgomet C, Neuvians TP. Determination of stable housekeeping genes, differentially regulated target genes and sample integrity:Best Keeper-excel-based tool using pair-wise correlations. Biotechnol Lett. 2004;26:509-515.

21. Kasai A, Ishimaru Y, Kinjo T et al. Apelin is a crucial factor for hypoxia-induced retinal angiogenesis. Arterioscler Thromb Vasc Biol. 2010;30:2182-2187. 
22. Han S, Wang G, Qi X, Lee HM, Englander EW, Greeley $\mathrm{GH}$. A possible role for hypoxia-induced apelin expression in enteric cell proliferation. Am J Physiol Regul Integr Comp. Physiol. 2008;294:1832-1839.

23. Fan TJ, Han LH, Cong RS, Liang J. Caspase family proteases and apoptosis. Acta Biochim Biophys Sin. 2005;37:719-727.

24. Zeng X, Yu SP, Taylor T et al. Protective effect of apelin on cultured rat bone marrow mesenchymal stem cells against apoptosis. Stem Cell. Res. 2012;8:357-367.

25. Xie H, Yuan LQ, Luo XH, Huang J, Cui RR, Guo LJ et al. Apelin suppresses apoptosis of human osteoblasts. Apoptosis. 2007;12:247-254.

26. Cui RR, Mao DA, Yi L et al. Apelin suppresses apoptosis of human vascular smooth muscle cells via APJ/PI3-K/Akt signaling pathways. Amino Acids. 2010;39:1193-1200.
27. Boiteux S, Radicella JP. The human OGG1 gene:structure, function, and its implication in then process of carcinogenesis. Arch Biochem Biophys. 2000;377:1-8.

28. Salmon TB, Evert BA, Song B, Doetsch PW. Biological consequences of oxidative stress-induced DNA damage in Saccharomyces cerevisiae. Nucl Acids Res. 2004;32:3712-3723.

29. Simonelli V, Narciso L, Dogliotti E, Fortini P. Base excision repair intermediates are mutagenie in mammalian cells. $\mathrm{Nucl}$ Acids Res. 2005;33:4404-4411.

30. Krokan HE, Standal R, Slupphaug G. DNA glycosylases in the base excision repair of DNA. Biochem J. 1997;325:1-16.

31. Nishioka K, Ohtsubo T, Oda $\mathrm{H}$ et al. Expression and differential intracellular localization of two major forms of human 8-oxoguanine DNA glycosylase encoded by alternatively spliced OGG1 mRNAs. Am Soc Cell Biol. 1999;10:1637-1652.

Submitted: 15 July, 2013 Accepted after reviews: 4 March, 2014 